\title{
EDITORIAL
}

\section{Un camino de Incertidumbre e Innovación.}

Nos hemos pasado cerca de treinta años -no ha sido posible de otra manerapara romper los muros manicomiales como instituciones totales, incorporando la asistencia psiquiátrica a la asistencia general a través de nuevos recursos y una nueva organización, y al ¿el? sistema sanitario al conjunto de los otros subsistemas. El incremento de dispositivos, su dotación adecuada, el cuidado de sus interrelaciones con el contexto social, ha presidido todo un esfuerzo consciente y colectivo. Bien, ha valido la pena.

Pretenden seducirnos institucionalmente con nuevos consensos basados en la experiencia acumulada y con nuevas intenciones de ampliar el estado del bienestar. Ocurre mientras necesitamos profundizar ¿todavía? en las realidades construidas y extraer las narrativas, las metodologías, éticas y valores imperantes, y valorar con más detenimiento las fortalezas y debilidades del constructo llamado psiquiatría comunitaria. Innovar desde la historia acumulada para profundizar en la otra psiquiatría. La psiquiatría comunitaria como una tecnología, como un sistema complejo que incluye una base científica de conocimientos de diversos campos, unos procedimientos técnicos basados en esos conocimientos, unos profesionales específicos y la interrelación permanente con el contexto social. La psiquiatría comunitaria precisamente cobra su sentido en los procesos intelectuales, afectivos, conductuales y éticos implícitos en la rehabilitación. La rehabilitación es más que una práctica. Probablemente debajo de la palabra amor se encuentran muchas relaciones y significados, al igual, que debajo de la palabra rehabilitación nos encontrarnos con diferentes realidades. Hay que sumergirse en las mismas y discriminar cuales están mas cerca de la bondad. Es una conversación pendiente con la realidad. Orientar mejor la organización y las actividades es contribuir a mejorar el estado de bienestar de los individuos y de la población.

El esfuerzo porque determinadas palabras dejen de serlo y cobren su sentido transformador nunca ha dejado de ser pertinente, más aun para la nueva década. Comunidad, continuidad de cuidados, misión, autonomía personal, clínica, recuperación, relación terapéutica, acompañamiento, interdisciplinariedad, atención en el propio domicilio, construcción de redes de redes, gestión clínica por procesos, son palabras que dotadas de su verdadero significado teórico y practico cobran una fuerza vital suficientemente arrolladora para construir un discurso vinculado al sujeto como protagonista, de acuerdo a sus narrativas personales, sus necesidades y en sus singulares procesos de "empowerment". Lejos están estas palabras de reducir la observación de las personas como cosas sometidas a pruebas estadísticas capaces de decirnos la verdad y la objetividad. 
EDITORIAL

En la atención centrada en la persona es donde se asienta la transformación. La participación de las personas entendida esta como tener el control para tomar decisiones y obtener este grado de control, cada vez es un sentimiento mas profundo en la ciudadanía. Esta demanda salpicará a toda la sociedad y también a nuestras iniciativas y a nuestras prácticas. Por ello la cultura de nuestra organización -léase sistema sanitario- debe estar impregnada de pensamientos y actos donde el otro está presente, no como mero formulismo o paternalismo, sino como esencia para la recuperación de su propia voz. La misión de la organización sanitaria, -fíjense que no digo los recursos de rehabilitación- no estará destinada a la estabilización de la psicopatología, sino orientada hacia la participación y recuperación, que probablemente conlleve incluso a cambiar muchos de los conceptos vigentes, por ejemplo, el concepto de hospitalización hoy para algunos inamovible.

Y si estas consideraciones están en la atmósfera, en la realidad de los ciudadanos se ha colado la posibilidad del reconocimiento de un nuevo derecho subjetivo: la situación de dependencia. Usted lector debería en este mismo número, en "Páginas de la Asociación", leer el informe de la Junta Directiva de la AEN al respecto. Sin entrar a valorar la viabilidad financiera de la ley, ni su partidaria politización, y ni siquiera, de las investigaciones del Tribunal de Cuentas del Estado en las Comunidades Autónomas ¿para la? distribución de los dineros para la ley de la dependencia, lo ciertoes que las personas con enfermedad mental grave son sujetos de la misma. Si la rehabilitación es una competencia sanitaria, la autonomía personal es uno de los ingredientes de la rehabilitación, y si se establecen marcos de cooperación sociosanitaria, llama la atención la frialdad en la actitud de las Consejerías de Sanidad de las Comunidades Autónomas- y cuando no ha habido intentos de separar de forma artificial lo agudo y lo crónico en redes diferentes- como si este asunto no tuviesen responsabilidades. Mas aún cuando la ley lleva tres años vigente en su aplicación. Entre otras consideraciones, con el fin de asegurar y desarrollar la calidad de las valoraciones (Resolución de 4 de febrero de 2010 de la Secretaría General de Política Social y Consumo) la AEN reclama que se haga efectiva la ampliación de la composición de los órganos de valoración con la incorporación de equipos técnicos de evaluación, asesoramiento y control, mediante la coordinación con otros equipos que en campos distintos atienden a las personas que se valoran, tal como recoge la citada resolución.

Para concluir, desde la AEN advertimos que, sino no ocurre un cambio en la aplicación de la ley, es muy probable que las expectativas positivas que se generaron inicialmente no se correspondan con la realidad, al no atenderse las necesidades para la autonomía personal de todas las personas con trastorno mental grave y no permitirse la renovación del sistema tradicional de atención basado 
EDITORIAL

en los cuidados familiares, así como, independientemente del color político de la administración, -al dirigir el 40-60\% de las prestaciones a ayudas económicas al cuidado familiar- no ofrecernos un marco de recursos y servicios variados de acuerdo al catalogo de prestaciones que contiene la ley.

Francisco Rodríguez Pulido 